\title{
Physician-Nurse Practitioner Teamwork in Primary Care Practices in New York: A Cross-Sectional Survey
}

\author{
Lusine Poghosyan ${ }^{1} \oplus$, Affan Ghaffari' , Jianfang Liu' , and Mark W. Friedberg' 2,3,4 \\ ${ }^{1}$ Columbia University School of Nursing, New York, NY, USA; ${ }^{2}$ RAND Corporation, California, USA; ${ }^{3}$ Brigham Women's Hospital, Boston, MA, USA; \\ ${ }^{4}$ Harvard Medical School, Boston, MA, USA.
}

BACKGROUND: Primary care practices increasingly rely on the growing workforce of nurse practitioners (NPs) to meet primary care demand. Understanding teamwork between NPs and physicians in primary care practices is critically important.

OBJECTIVE: We assessed teamwork between NPs and physicians practicing within the same primary care practice and determined how teamwork affects their job satisfaction, intent to leave their current job, and quality of care.

DESIGN: A cross-sectional survey design was used to collect data from both NPs and physicians in New York State in 2017.

PARTICIPANTS: 584 participants (398 NPs and 186 physicians) from 476 primary care practices completed the survey yielding a $27 \%$ response rate for NPs and $12 \%$ for physicians.

MAIN MEASURES: The survey tool contained validated measures of teamwork and three outcomes: job satisfaction, intent to leave, and perceived quality of care. Simple and multi-level multivariable regression models were built. KEY RESULTS: Most participants (76\%) were either moderately satisfied or very satisfied with their job (NP sample: $75 \%$; physician sample: $77 \%$ ) and about $10 \%$ intended to leave their current job (NP sample: 11\%; physician sample: $9 \%$ ). The average perceived quality of care was the same across NP and physician samples with a mean of 8.5 on a 11 point scale. After controlling for confounders, a higher organizational-level teamwork score was associated with higher job satisfaction (cumulative OR: 3.00; 95\% CI: 1.85-4.88), lower odds of intent to leave (OR: 0.25 ; 95\% CI: 0.09-0.74), and higher perceived quality of care (b=1.00; 95\% CI: 0.77-1.23).

CONCLUSIONS: This study produced evidence about NPphysician teamwork in primary care practices. We found the vast majority of NPs and physicians reported favorable teamwork, and that teamwork affects clinician job satisfaction and intent to leave as well as perceived quality of care in their practices.

KEYWORDS: primary care; teamwork; nurse practitioners; physician; job satisfaction; intent to leave; quality of care.

J Gen Intern Med 35(4):1021-8

DOI: $10.1007 / \mathrm{s} 11606-019-05509-2$

(C) Society of General Internal Medicine 2020

Received May 31, 2019

Revised September 13, 2019

Accepted October 18, 2019

Published online January 6, 2020

\section{BACKGROUND}

Team-based care models are viewed as critical for redesigning primary care delivery in the United States (U.S.) to meet the increased demand for timely, high quality, patient-centered care 1 . Team-based care promotes effectiveness and value of primary care and increases its capacity ${ }^{2-4}$. In response, many primary care practices have adopted team-based care delivery models ${ }^{5}$. Currently, physicians, physician assistants, and nurse practitioners (NPs) deliver the bulk of primary care services, with physicians and NPs comprising about $90 \%$ of the total primary care provider (PCP) workforce ${ }^{6}$. While most PCPs are physicians, projections show that NPs (whose numbers are predicted to increase by $93 \%$ between 2013-2025) will comprise about one-third of the total PCP workforce in $2025^{6}$. Currently, primary care practices increasingly rely on the NP workforce ${ }^{7}$.

Primary care teams comprised of NPs and physicians hold potential in meeting the growing demand for care and improving its quality. However, designing interdisciplinary teams and bringing together members with varied training and skillsets is challenging. Studies from organizational and business management studies have shown that teams comprised of members with diverse characteristics, skills, and competencies can be efficient, creative, and productive ${ }^{8,9}$. However, these teams also often experience conflict and miscommunication ${ }^{8,10,11}$, which can reduce job satisfaction and lead to turnover and other negative outcomes such as absenteeism ${ }^{12-15}$.

As NPs are beginning to more frequently serve as PCPs and work in teams alongside physicians, it is critical to understand how teamwork between these providers affects their work experiences. Assuring positive work experiences for clinicians is a national priority as indicated in the National Academy of Medicine's recent Action Collaborative on Clinician WellBeing and Resilience initiative ${ }^{16}$. Studies have evaluated the impact of NP-physician teams on patient outcomes but have not investigated how teamwork affects clinician outcomes such as job satisfaction or turnover ${ }^{17}$. Furthermore, most studies to date have focused only on specific perspectives of either NPs or physicians, but not both, especially of those working in the same practice. Given different educational backgrounds and professional identities of these PCPs, it is important to understand their perspectives about teamwork and its impact on their 
outcomes. We investigated the perspectives of both NPs and physicians practicing within the same primary care practice on teamwork and determined how teamwork affects their job satisfaction, intent to leave, and quality of care.

\section{METHODS}

\section{Design}

We used a cross-sectional survey design to collect data from PCPs (both NPs and physicians) in New York State in 2017. The study was approved by the Institutional Review Board of Columbia University Irving Medical Center (approval \#: AAAQ5708).

\section{Sample}

We used the SK\&A database to identify primary care practices employing both NPs and physicians in New York State ${ }^{18}$. The database allows identifying both NPs and physicians practicing within the same practice ${ }^{18}$. We used physician specialties to determine primary care practices as physician specialty is likely to drive the practice type ${ }^{19}$. The following specialties were used: family medicine, general practice, internal medicine, internal medicine/pediatrics, internal medicine/ preventive medicine, general preventive medicine, and geriatrics. Following the approach of Barnes et al., for practices with a mix of both primary care and specialty physicians, we designated a practice as primary care if the majority of physicians within the practice were primary care physicians ${ }^{19}$. We first extracted practice addresses of all NPs in primary care practices in New York State and then drew a $20 \%$ random sample of physicians from these practices since there were about 5 times more physicians than NPs. Overall, we extracted contact information for 1,590 NPs and 1,592 physicians.

\section{Survey Tool}

The survey tool contained measures of teamwork, job satisfaction, intent to leave, and quality of care. The teamwork measure, used in previous research, asks PCPs to report their perception about various aspects of teamwork including whether NPs and physicians collaborate to provide patient care or practice as a team ${ }^{20}$. The measure consisted of 5 items reported on a 4-point scale ranging from " 1 - strongly disagree" to "4 - strongly agree". PCPs reported their job satisfaction on a 4-point scale (1-"very dissatisfied" to 4-"very satisfied") as well. Intent to leave was measured using a dichotomous item probing whether PCPs intended to leave their position within the next year (yes/no). Perceived quality of care was measured by asking PCPs to rate the quality of care within their practices on an 11-point scale ("0" as "worst care possible" to " 10 " as "best care possible").

The survey tool also collected demographic information such as age, sex, race, and education. Some questions were tailored for NPs and physicians to collect relevant information.

\section{Data Collection}

After extracting contact information, paper surveys were mailed to 3,182 PCPs using their practice addresses. A letter and consent form - which described the study, its voluntary nature, and the confidentiality of responses - accompanied the survey. PCPs completed the survey and returned it in an enclosed prepaid envelope to the research team. Using a modified Dillman approach for mailed surveys to encourage maximum response rate, a postcard reminder was sent to non-respondents 2 weeks after the initial mailing and then a second mail survey was sent to nonrespondents ${ }^{21}$. As an incentive, PCPs were offered an opportunity to participate in a lottery drawing to win 1 of 30 FitBit Zips.

\section{Data Analysis}

The data was entered into SPSS $24{ }^{22}$, cleaned, coded, and checked for accuracy. Descriptive statistics on PCP demographic variables were computed. We assessed the internal consistency of the teamwork scale by computing the Cronbach's $\alpha$ at organizational-level. We also computed generalizability coefficients to assess the measurement errors from multiple sources by considering the hierarchical nature of the data (e.g., PCPs nested within practices). G coefficient as relative generalizability coefficient and $\Phi$ coefficient as absolute generalizability coefficient were computed to assess the dependability of the scale $^{23}$. We first created the individual PCP's teamwork score by computing the mean of the items comprising the scale and then aggregated the scores of all respondents from each practice and computed organizational-level teamwork mean scores. We also dichotomized the items on the teamwork scale by combining the positive "3-agree" and "4-strongly agree" responses into 1 category and the negative "1- strongly disagree" and "2disagree" responses into another category. We computed the percentages of NPs and physicians endorsing the positive responses and tested the mean differences between the groups.

Finally, we examined the effects of organizational-level teamwork scale on each of the outcome variables (i.e. job satisfaction, intent to leave, and perceived quality of care) separately. We used proportional-odds cumulative logit models for job satisfaction as it was measured on a 4-point Likert scale, binary logistic regression models for intent to leave, and linear regression models for perceived quality of care ${ }^{24}$. We used linear regression models for the outcome perceived quality of care as it was measured on an 11-point Likert scale; and studies show that Likert or ordinal variables with 5 or more categories can often be used as continuous without any noticeable harm to the analysis ${ }^{25,26}$. We tested if the outcome measures were the same for the physician and NP samples to assure that we could build a final model for each outcome by combining the data from both samples. Using simple regression models, we first assessed the bivariate association between each potential covariate and the outcome variables. Profession indicator (2 groups: physician vs NP) was also included in each final model as an important covariate associated with the outcomes. The final models accounted for the hierarchical design of the data, where 584 participants (Level-1) were 
nested in 476 practices (Level-2). Covariates measuring PCP demographics and work characteristics were entered as Level-1 measures. The main predictor was the organizational-level teamwork scale (Level-2). With 476 practices, we had a sufficient sample size to obtain accurate estimates for the organizationallevel predictor ${ }^{27}$. Unadjusted and adjusted cumulative odds ratios were reported for job satisfaction, odds ratio for intent to leave, and regression coefficient for quality of care, along with 95\% confidence intervals (CIs) to assess the strength and direction of the effects. We also conducted subgroup analysis only including participants from practices with at least $1 \mathrm{NP}$ and at least 1 physician in each practice to ensure that we have robust results. Data analysis was conducted in SAS $9.4^{28}$.

\section{RESULTS}

A total of 584 PCPs completed the survey: 398 NPs (27\% response rate) and 186 physicians (12\% response rate). To test the response bias by geographic location, we linked the zip codes of practices to the Rural Urban Commuting Area codes ${ }^{29}$ to classify each primary care practice as urban or rural. We assessed whether PCPs from different geographic areas (i.e., urban or rural) were more likely to respond to our survey and found no significant difference in the response rate between participants from urban (19\%) and rural (23\%) practices ( $\mathrm{p}=.08$ ). Among the 476 practices in the study, 82 (19\%) practices had at least $1 \mathrm{NP}$ and 1 physician.

Table 1 presents the descriptive statistics on the demographic and work characteristics of participants and the outcome measures. The average age of the participants was about 53 years $(\mathrm{SD}=11.5)$ with physicians being significantly older than NPs $(\mathrm{p}<0.05)$. Most participants were female $(76 \%)$ and white $(86 \%)$. However, the percentage of females in the NP sample $(92 \%)$ was significantly higher than that in the physician sample $(41 \%)(\mathrm{p}<0.05)$.

Table 1 Demographic and Work Characteristics of Study Participants

\begin{tabular}{|c|c|c|c|c|}
\hline & $\begin{array}{l}\text { Total } \\
(N=584)\end{array}$ & $\begin{array}{l}\text { Physicians } \\
(N=186)\end{array}$ & $\begin{array}{l}\text { NPs } \\
(N=398)\end{array}$ & $P$ \\
\hline \multicolumn{5}{|c|}{ Demographic Characteristics } \\
\hline Age $*$ & $\begin{array}{l}\text { Mean (SD) } \\
52.6(11.5) \\
\%(\mathrm{n})\end{array}$ & $\begin{array}{l}\text { Mean (SD) } \\
55.8(10.6) \\
\%(\mathrm{n})\end{array}$ & $\begin{array}{l}\text { Mean (SD) } \\
50.9(11.5) \\
\%(\mathrm{n})\end{array}$ & $<0.001$ \\
\hline \multicolumn{5}{|l|}{ Sex } \\
\hline \multicolumn{5}{|l|}{ Race } \\
\hline \multicolumn{5}{|l|}{ Educational level } \\
\hline \multirow{2}{*}{ Work Characteristics } & $36(210)$ & $98(183)$ & $7(27)$ & \multirow[t]{2}{*}{$<0.001$} \\
\hline & $\%(\mathrm{n})$ & $\%(\mathrm{n})$ & $\%(\mathrm{n})$ & \\
\hline \multicolumn{5}{|l|}{ Practice setting } \\
\hline $\begin{array}{l}\text { Physician office } \\
\text { Hospital practice }\end{array}$ & $58(339)$ & $63(118)$ & $56(221)$ & \multirow[t]{3}{*}{0.11} \\
\hline $\begin{array}{l}\text { Hospital practice } \\
\text { Community health }\end{array}$ & $\begin{array}{l}18(103) \\
9(52)\end{array}$ & $\begin{array}{l}17(31) \\
10(18)\end{array}$ & $18(72)$ & \\
\hline \multicolumn{4}{|l|}{ clinic } & \\
\hline Hours worked in past $\mathrm{w}$ & & & & \multirow{4}{*}{$<0.001$} \\
\hline $1-20$ hours & $7(43)$ & $6(11)$ & $8(32)$ & \\
\hline 21-40 hours & $51(295)$ & $40(73)$ & $56(222)$ & \\
\hline $40+$ hours & $42(240)$ & $54(99)$ & $36(141)$ & \\
\hline \multicolumn{5}{|c|}{ Length of time in current primary position } \\
\hline$<3$ years & $21(123)$ & $14(26)$ & $25(97)$ & \multirow[t]{3}{*}{$<0.001$} \\
\hline 4-9 years & $28(165)$ & $22(41)$ & $31(124)$ & \\
\hline $10+$ years & $51(295)$ & 64 (119) & 44 (176) & \\
\hline \multicolumn{5}{|c|}{ Total number of NPs in practice } \\
\hline 1 & $22(125)$ & $17(31)$ & $24(94)$ & \multirow[t]{3}{*}{$<0.001$} \\
\hline $2-6$ & $63(365)$ & $54(100)$ & $67(265)$ & \\
\hline $7+$ & $15(89)$ & $29(54)$ & $9(35)$ & \\
\hline \multicolumn{5}{|l|}{ Patient panel size } \\
\hline$<100$ & $28(98)$ & $13(14)$ & $35(84)$ & \multirow[t]{3}{*}{$<0.001$} \\
\hline $100-999$ & $36(125)$ & $19(21)$ & 44 (104) & \\
\hline$>=1000$ & $36(124)$ & $68(73)$ & $21(51)$ & \\
\hline Own patient panel ${ }^{\dagger}$ & $58(338)$ & $68(127)$ & $53(211)$ & $<0.001$ \\
\hline \multicolumn{5}{|l|}{ Job satisfaction } \\
\hline Very dissatisfied & $12(68)$ & $8(14)$ & $14(54)$ & \multirow[t]{4}{*}{0.12} \\
\hline A little dissatisfied & $12(71)$ & $15(27)$ & $11(44)$ & \\
\hline Moderately Satisfied & 35 (199) & $37(68)$ & $33(131)$ & \\
\hline Very Satisfied & $41(239)$ & $40(73)$ & $42(166)$ & \\
\hline \multirow{2}{*}{ Intent to leave job ${ }^{\dagger}$} & $10(55)$ & $9(15)$ & $11(40)$ & \multirow{2}{*}{0.46} \\
\hline & Mean (SD) & Mean (SD) & Mean (SD) & \\
\hline Quality of care ${ }^{*} \S$ & $8.5(1.3)$ & $8.5(1.2)$ & $8.5(1.4)$ & 0.96 \\
\hline
\end{tabular}

${ }^{*}$ A $t$ - test generated p-value.

"Dichotomous item (yes/no)- \% that responded "yes."

"4-point scale ("1-very dissatisfied" to "4-very satisfied").

\$11-point scale ("0" as "worst care possible" to "10" as "best care possible"). 
The outcome variables did not vary between NPs and physicians. Most of the participants were either moderately satisfied or very satisfied with their job and only about $10 \%$ intended to leave their job. The average perceived quality of care (on a 11-point scale, higher indicating better quality of care) in the overall sample was 8.5.

\section{Organizational-level Teamwork Scale and Outcomes}

The descriptive statistics and the reliability coefficients on the teamwork items and scale are presented in Table 2. On average, PCPs reported an organizational-level teamwork score of 3.47 on a 4-point scale which indicated agreement that key teamwork attributes were present within their practices. The organizational-level teamwork scale had acceptable internal consistency reliability (Cronbach's $\alpha=0.85$ ) and dependability ( $G$ coefficient $=0.85 ; \Phi$ coefficient $=0.82$ ). The descriptive statistics on individual teamwork items for NPs and physicians are presented in Table 3. At least $89 \%$ of NPs and physicians reported favorable aspects of teamwork within their practices on all 5 items. More than $90 \%$ of NPs and physicians reported that NPs and physicians practice as a team.

Unadjusted effects of the organizational-level teamwork scale and each covariate are reported in Table 4. Without controlling for any covariates, a higher organizational-level teamwork score was associated with a higher category of job satisfaction, $71 \%$ lower odds of intent to leave current job, and higher perceived quality of care. Only covariates with p-value less than 0.20 in the bivariate analysis were included in the final multi-level multivariable regression models presented in Tables 5 and 6 . As none of the outcome measures were different between physicians and NPs, we built the multilevel multivariable final models using the aggregated sample and included profession indicator (physician vs NP) as a

Table 2 Descriptive Statistics of Teamwork Scale and Items

\begin{tabular}{|c|c|c|c|c|}
\hline Items & $\begin{array}{l}\text { Mean } \\
\text { (SD) }\end{array}$ & Min & Max & $\begin{array}{l}\text { Item- } \\
\text { deleted } \\
\text { Cronbach } \\
\alpha\end{array}$ \\
\hline \multicolumn{5}{|l|}{ Item-Level* } \\
\hline $\begin{array}{l}\text { Physicians support NP } \\
\text { patient care decisions }\end{array}$ & $\begin{array}{l}3.51 \\
(0.58)\end{array}$ & 1 & 4 & 0.82 \\
\hline $\begin{array}{l}\text { I feel valued by my } \\
\text { colleagues }\end{array}$ & $\begin{array}{l}3.39 \\
(0.70)\end{array}$ & 1 & 4 & 0.82 \\
\hline $\begin{array}{l}\text { In my organization, NPs } \\
\text { and physicians collaborate to } \\
\text { provide patient care }\end{array}$ & $\begin{array}{l}3.46 \\
(0.64)\end{array}$ & 1 & 4 & 0.79 \\
\hline $\begin{array}{l}\text { In my organization, } \\
\text { physicians and NPs practice } \\
\text { as a team }\end{array}$ & $\begin{array}{l}3.42 \\
(0.68)\end{array}$ & 1 & 4 & 0.79 \\
\hline $\begin{array}{l}\text { In my practice setting, I } \\
\text { have colleagues who I can } \\
\text { ask for help }\end{array}$ & $\begin{array}{l}3.57 \\
(0.60)\end{array}$ & 1 & 4 & 0.87 \\
\hline \multicolumn{5}{|l|}{ Scale-Level } \\
\hline $\begin{array}{l}\text { Organizational-level } \\
\text { Teamwork Scale }\end{array}$ & $\begin{array}{l}3.47 \\
(0.46)\end{array}$ & 1.6 & 4 & $0.85 \dagger$ \\
\hline
\end{tabular}

Note. $N=584$.

*Items reported on 4-point scale ("1- strongly disagree" to "4-strongly agree").
Table 3 Physician and NP Responses on Teamwork Items

\begin{tabular}{|c|c|c|c|c|}
\hline \multirow[t]{2}{*}{$\overline{\text { Item }}$} & \multirow{2}{*}{$\begin{array}{l}\begin{array}{l}\text { Total } \\
(N=584)\end{array} \\
\%(n)\end{array}$} & \multirow{2}{*}{$\begin{array}{l}\begin{array}{l}\text { Physicians } \\
(N=186)\end{array} \\
\%(\mathrm{n})\end{array}$} & \multirow{2}{*}{$\begin{array}{l}\begin{array}{l}\text { NPs } \\
(N=398)\end{array} \\
\%(n)\end{array}$} & \multirow[t]{2}{*}{$P\left(\chi^{2}\right)$} \\
\hline & & & & \\
\hline $\begin{array}{l}\text { Physicians support } \\
\text { NP patient care } \\
\text { decisions }\end{array}$ & 97 (557) & 97 (174) & 97 (383) & 0.75 \\
\hline $\begin{array}{l}\text { I feel valued by my } \\
\text { colleagues }\end{array}$ & $90(522)$ & 94 (170) & 89 (352) & 0.06 \\
\hline $\begin{array}{l}\text { In my organization, } \\
\text { NPs and physicians } \\
\text { collaborate to provide } \\
\text { patient care }\end{array}$ & $94(543)$ & 96 (172) & 94 (371) & 0.43 \\
\hline $\begin{array}{l}\text { In my organization, } \\
\text { physicians and NPs } \\
\text { practice as a team }\end{array}$ & $91(526)$ & $91(163)$ & $92(363)$ & 0.66 \\
\hline $\begin{array}{l}\text { In my practice setting, } \\
\text { I have colleagues who } \\
\text { I can ask for help }\end{array}$ & $96(553)$ & 91 (166) & 97 (387) & $<0.001$ \\
\hline
\end{tabular}

Note. All items were reported on 4-point scale ("1- strongly disagree" to "4-strongly agree"). Percentages indicate those who responded "3agree" or "4-strongly agree" to the item.

covariate. After adjusting for effects of potential covariates, a higher organizational-level teamwork score was associated with higher job satisfaction (cumulative $\mathrm{OR}=3.00 ; 95 \% \mathrm{CI}$ : $1.85-4.88, \mathrm{p}<0.05)$; with a 1 -unit increase in the organizational-level teamwork score, the odds of a higher job satisfaction category nearly tripled. Controlling for confounders, a higher organizational-level teamwork score was associated with lower odds of intent to leave current job (OR: 0.25 ; 95\% CI: 0.09-0.74, $\mathrm{p}<0.05$ ) with a 1-unit increase in the organizational-level teamwork score, the odds of intent to leave current job decreased by $75 \%$. No other covariate had a significant effect on intent to leave current job after controlling for the organizational-level teamwork score. A higher organizational-level teamwork score was associated with higher perceived quality of care $(b=1.00 ; 95 \%$ CI: $0.77-1.23$, $\mathrm{p}<0.05)$. Specifically, with a 1-unit increase in the teamwork score, there was 1-unit increase in the perceived quality of care.

In addition, we performed subgroup analysis that only included practices with at least $1 \mathrm{NP}$ and 1 physician. This analysis included 182 participants with 95 NPs and 87 physicians from 82 practices. The effects of the organizational-level teamwork score on the 3 outcomes were similar to those of the full sample (see Table 6). After adjusting for the effects of potential covariates, a higher organizational-level teamwork score was associated with higher job satisfaction (cumulative OR: 4.75; 95\% CI: 1.34-16.80, p<0.05), lower odds of intent to leave current job (OR: $0.12 ; 95 \%$ CI: $0.01-0.93$, p $<0.05$ ), and higher perceived quality of care $(b=1.18 ; 95 \%$ CI: $0.53-$ $1.83, \mathrm{p}<0.05)$.

\section{DISCUSSION}

We investigated teamwork between NPs and physicians and how it affected job satisfaction, intent to leave, and perceived 
Table 4 Simple Regression Models Assessing the Unadjusted Effect of Each Independent Variable on Job Satisfaction, Intent to Leave Current Job, and Quality of Care

\begin{tabular}{|c|c|c|c|c|c|c|}
\hline \multirow[b]{2}{*}{ Predictor } & \multicolumn{2}{|l|}{ Job Satisfaction } & \multicolumn{2}{|c|}{ Intent to Leave } & \multicolumn{2}{|l|}{ Quality of Care } \\
\hline & Cumulative OR & $95 \% \mathrm{CI}$ & OR & $95 \% \mathrm{CI}$ & Regression Coefficient & $95 \% \mathrm{CI}$ \\
\hline Organizational-level teamwork subscale & $3.01^{\S}$ & $2.14,4.24$ & $0.29^{\S}$ & $0.16,0.51$ & $1.11 \S$ & $0.90,1.33$ \\
\hline Age & 1.01 & $0.99,1.02$ & 0.99 & $0.97,1.02$ & $0.01^{\dagger}$ & $0.002,0.02$ \\
\hline Male & 0.97 & $0.68,1.37$ & $0.60^{*}$ & $0.29,1.27$ & -0.08 & $-0.34,0.17$ \\
\hline White & 1.00 & $0.64,1.56$ & 1.04 & $0.47,2.30$ & 0.08 & $-0.23,0.39$ \\
\hline Doctoral degree & 0.91 & $0.66,1.24$ & 1.41 & $0.76,2.59$ & 0.01 & $-0.22,0.23$ \\
\hline NP (Ref: physician) & 0.97 & $0.70,1.33$ & 1.26 & $0.68,2.35$ & -0.01 & $-0.24,0.23$ \\
\hline \multicolumn{7}{|c|}{ Length of time in current primary position (Ref: $>=10$ years) } \\
\hline$<=3 \mathrm{yr}$ & 0.75 & $0.50,1.10$ & $1.89+$ & $0.99,3.61$ & $-0.39+$ & $-0.66,-0.11$ \\
\hline $\begin{array}{l}\text { 4-9yr } \\
\text { Practice setting (Ref: physician's office) }\end{array}$ & $0.75^{*}$ & $0.53,1.06$ & $0.85^{*}$ & $0.42,0.75$ & $-0.47^{\S}$ & $-0.72,-0.23$ \\
\hline \multicolumn{7}{|l|}{ Practice setting (Ref: physician's office) } \\
\hline $\begin{array}{l}\text { Community health center } \\
\text { Hosnital based clinic }\end{array}$ & 0.74 & $0.43,1.27$ & 2.13 & $0.94,4.80$ & $-0.52+$ & $-0.90,-0.14$ \\
\hline Hospital based clinic & $0.66^{\dagger}$ & $0.45,0.99$ & 1.17 & $0.55,2.49$ & $-0.72^{\#}$ & $-1.00,-0.43$ \\
\hline Other & 1.19 & $0.76,1.85$ & $0.75^{+}$ & $0.30,1.86$ & -0.19 & $-0.49,0.11$ \\
\hline \multicolumn{7}{|c|}{ Hours worked in past week (Ref: $>40$ hours) } \\
\hline $20-40$ & 1.05 & $0.77,1.44$ & 0.95 & $0.53,1.71$ & 0.10 & $-0.13,0.33$ \\
\hline$<=20 \mathrm{hrs}$ & 1.40 & $0.76,2.58$ & 1.27 & $0.45,3.56$ & -0.04 & $-0.48,0.39$ \\
\hline Having own panel & 0.92 & $0.68,1.25$ & 1.34 & $0.77,2.35$ & 0.01 & $-0.21,0.23$ \\
\hline \multicolumn{7}{|l|}{ Total \# of NPs in practice (Ref: $1 \mathrm{NP}$ ) } \\
\hline 2-6 NPs & 1.22 & $0.84,1.77$ & $1.53^{*}$ & $0.72,3.25$ & -0.12 & $-0.38,0.15$ \\
\hline$>6$ NPs & $1.92^{\dagger}$ & $1.16,3.19$ & 0.92 & $0.31,2.69$ & -0.04 & $-0.40,0.32$ \\
\hline \multicolumn{7}{|l|}{ Patient panel size (Ref: <100) } \\
\hline $100-1000$ & 0.82 & $0.50,1.35$ & $0.86_{*}$ & $0.34,2.22$ & 0.18 & $-0.40,0.30$ \\
\hline$>1000$ & 0.73 & $0.45,1.20$ & $1.46^{*}$ & $0.62,3.48$ & 0.18 & $-0.42,0.29$ \\
\hline
\end{tabular}

Note. $N=584$.

${ }^{*} p<.20$.

$p<.05$

${ }_{p}<.01$.

$\xi_{p}<.001$.

quality of care. We found that the vast majority of NPs and physicians reported favorable teamwork and there were no differences between NP and physician reports. Physician outcomes were slightly more positive than NP outcomes; a higher percentage of physicians reported being satisfied with their job and a lower percentage of physicians reported an intent to leave. However, the difference was not statistically significant. Both NPs and physicians rated the quality of care within their practices similarly. Even though we used perceived quality of care rather than clinical data, this finding is consistent with the literature documenting similar quality of care in practices delivered by NPs and physicians ${ }^{30,31}$.

We also found teamwork between NPs and physicians being an important predictor of their outcomes. PCPs delivering care in practices with better teamwork are more likely to report higher job satisfaction, less intent to leave their job, and better

Table 5 Final Multi-Level Regression Models Assessing the Effect of Organizational-Level Teamwork on Job Satisfaction, Intent to Leave, and Quality of Care

\begin{tabular}{|c|c|c|c|c|c|c|}
\hline \multirow[b]{2}{*}{ Predictor } & \multicolumn{2}{|l|}{ Job Satisfaction } & \multicolumn{2}{|c|}{ Intent to Leave $^{\dagger}$} & \multicolumn{2}{|l|}{ Quality of Care * } \\
\hline & Cumulative OR & $95 \%$ CI & OR & $95 \% \mathrm{CI}$ & Regression Coefficient & $95 \% \mathrm{CI}$ \\
\hline Organizational-level Teamwork Subscale & $3.00^{\dagger}$ & $1.85,4.88$ & $0.25^{*}$ & $0.09,0.74$ & $1.00^{*}$ & $0.77,1.23$ \\
\hline NP (Ref:Physician) & 1.00 & $0.62,1.63$ & 1.50 & & 0.04 & $-0.18,0.26$ \\
\hline Age & - & - & - & - & 0.01 & $-0.003,0.02$ \\
\hline Male & - & - & 0.89 & $0.20,3.87$ & - & - \\
\hline \multicolumn{7}{|c|}{ Length of time in current primary position (Ref: $>=10$ years) } \\
\hline$<=3 \mathrm{yr}$ & 0.93 & $0.54,1.61$ & 1.58 & $0.46,5.44$ & -0.04 & $-0.34,0.26$ \\
\hline $4-9 \mathrm{yr}$ & 0.80 & $0.49,1.32$ & 0.62 & $0.18,2.14$ & -0.23 & $-0.48,0.03$ \\
\hline \multicolumn{7}{|l|}{ Practice setting (Ref: physician's office) } \\
\hline Community health center & 0.68 & $0.31,1.46$ & 2.80 & $0.62,12.74$ & $-0.42^{*}$ & $-0.78,-0.07$ \\
\hline Hospital based clinic & 0.71 & $0.39,1.28$ & 0.83 & $0.21,3.32$ & $-0.47^{\dagger}$ & $-0.74,-0.19$ \\
\hline Other & 1.05 & $0.57,1.96$ & 0.55 & $0.10,3.07$ & -0.15 & $-0.44,0.14$ \\
\hline \multicolumn{7}{|l|}{ Total \# of NPs in practice (Ref: $1 \mathrm{NP}$ ) } \\
\hline 2-6 NPs & 1.20 & $0.72,2.02$ & 1.66 & $0.44,6.19$ & - & - \\
\hline$>6 \mathrm{NPs}$ & $2.17^{\dagger}$ & $1.02,4.61$ & 1.28 & $0.19,8.53$ & - & - \\
\hline \multicolumn{7}{|l|}{ Patient panel size (Ref: <100) } \\
\hline $100-1000$ & & & 0.94 & $0.18,4.97$ & & \\
\hline$>1000$ & & & 1.96 & $0.38,10.1$ & & \\
\hline
\end{tabular}

Note. $N=584$.

* $p<.05$.

$p<.01$.

$p<.001$. 
Table 6 Subgroup Analysis Assessing the Effect of Organizational-Level Teamwork on Job Satisfaction, Intent to Leave, and Quality of Care,

\begin{tabular}{|c|c|c|c|c|c|c|}
\hline \multirow[b]{2}{*}{ Predictor } & \multicolumn{2}{|l|}{ Job Satisfaction } & \multicolumn{2}{|c|}{ Intent to Leave $^{\dagger}$} & \multicolumn{2}{|l|}{ Quality of Care } \\
\hline & Cumulative OR & $95 \% \mathrm{CI}$ & OR & $95 \% \mathrm{CI}$ & Regression Coefficient & $95 \% \mathrm{CI}$ \\
\hline $\begin{array}{l}\text { Organizational-level Teamwork Subscale } \\
\text { NP (Ref:physician) } \\
\text { Age } \\
\text { Practice setting (Ref: physician's office) } \\
\text { Community health center } \\
\text { Hospital based clinic } \\
\text { Other } \\
\text { Hours worked in past week (Ref: }>40 \text { hours) } \\
20-40 \\
<20 \text { hrs } \\
\text { Own patient panel }{ }^{\dagger}\end{array}$ & $\begin{array}{l}4.75^{*} \\
0.84 \\
1.00 \\
0.45 \\
0.71^{\dagger} \\
1.63 \\
2.38^{*} \\
4.55^{*} \\
-\end{array}$ & $\begin{array}{l}1.34,16.8 \\
0.45,1.58 \\
0.97,1.03 \\
0.11,1.90 \\
0.27,1.87 \\
0.52,5.12 \\
1.18,4.80 \\
1.05,19.7 \\
-\end{array}$ & $\begin{array}{l}0.12^{*} \\
1.92 \\
- \\
- \\
- \\
- \\
- \\
- \\
- \\
3.60^{*}\end{array}$ & $\begin{array}{l}0.01,0.93 \\
0.61,6.01 \\
- \\
- \\
- \\
- \\
- \\
- \\
- \\
1.02,12.62\end{array}$ & $\begin{array}{l}1.18^{\ddagger} \\
0.15 \\
0.01^{*} \\
\\
-0.08 \\
-0.71^{\dagger} \\
-0.11 \\
0.34 \\
0.01 \\
-\end{array}$ & $\begin{array}{l}0.53,1.83 \\
-0.23,0.53 \\
0.005,0.04 \\
-0.89,0.73 \\
-1.25,-0.18 \\
-0.73,0.50 \\
-0.06,0.74 \\
-0.78,0.81 \\
-\end{array}$ \\
\hline
\end{tabular}

quality of care. Even after controlling for many factors such as age, sex, length of time in current position, practice type, and practice size in final models, teamwork was the only significant predictor across all 3 outcomes. In fact, for 2 of the outcomes job satisfaction and intent to leave - teamwork was the only significant predictor, further underscoring the importance of teamwork in shaping clinician outcomes. These findings are consistent with evidence about the importance of teamwork in promoting clinician outcomes and quality of care ${ }^{32}$.

\section{IMPLICATIONS FOR POLICY, PRACTICE, AND RESEARCH}

The study findings have important implications for policy, practice, and research. Job satisfaction and intent to leave are critical outcomes to focus on in policy interventions given the widespread dissatisfaction among clinicians including physicians ${ }^{33}$ and NPs ${ }^{34}$. This has fueled a renewed focus on "bringing joy back to practice" ${ }^{35}$ and development of the Quadruple Aim (i.e., improving patient experience, bolstering population health, reducing cost of patient care and enhancing the work life of health care providers) to improve the work life of clinicians and staff ${ }^{36}$. In addition, negative PCP outcomes may deplete primary care practices from much needed workforce resources and adversely affect patient outcomes. Given the increasing demand for primary care, team-based care can help to meet the demand and assure clinician well-being. Thus, it is critically important to build effective primary care teams in the current policy environment.

Several factors should be considered for promoting teamwork in primary care and subsequently improving clinician outcomes. In the U.S., NPs are allowed to deliver care to the fullest extent of their education in only 23 states ${ }^{37}$. The remaining states restrict NP practice by requiring supervision or oversight by physicians. Such policies, which limit the practice of a team member, may undermine teamwork and prevent NPs from fully contributing their skills to their teams. Thus, policy changes promoting full NP practice are necessary in many states as a first step to promote optimal teamwork. Improvements can also be made at the practicelevel to promote teamwork and consequently clinician outcomes. Slightly more positive outcomes reported by physicians may be indicative of better policies and organizational environments for physicians compared to NPs (e.g., greater autonomy of practice) which may be created by the practice administration. Research shows that practice administrators in primary care practices play a critical role in promoting or hindering teamwork between NPs and physicians ${ }^{20}$. Thus, increasing administrators' awareness about optimal teamwork and designing and implementing organizational-level interventions to improve teamwork is necessary ${ }^{38}$. Future research should be conducted on the organizational and individual-level factors contributing to PCP job satisfaction and intent to leave.

The study has limitations. First, it relies on PCP self-reports which are subject to socially desirable response bias. Additionally, data was collected in 1 state (NY) with a reduced scope of practice for NPs where new NPs are required to have a written practice agreement with physicians to deliver care ${ }^{39}$. The findings may not be generalizable to other states with different NP scope of practice regulations (e.g., restricted or full scope of practice) or different regions of the country. Also, roughly $80 \%$ of practices only had 1 respondent per practice. However, the subgroup analysis showed practices with multiple respondents per practice had similar findings to that of the full sample. Response rate may also be a limitation. However, in another study using SK\&A databases in 6 states (NY not included), we conducted a phone survey of NP nonresponders. We selected a random sample of $600 \mathrm{NPs}$ and called their practices only once and found that $24 \%$ of NPs either did not work there, never worked there, or had inaccurate contact information, which did not allow our survey to reach them. Based on this, we estimated $24 \%$ of NPs (382 individuals) may have been unreachable. By excluding undelivered mails and the estimated number of unreachable NPs, we could achieve a response rate of $36 \%$ for NPs. 


\section{CONCLUSION}

Teamwork is important in shaping PCP job satisfaction, intent to leave, and quality of care. It is important for primary care initiatives to consider teamwork between NPs and physicians and how to promote it.

Acknowledgements: Contributors: None

Corresponding Author: Lusine Poghosyan, Columbia University School of Nursing, 617 W. 168th Street, Mail Code 6, New York, NY 10032, USA (e-mail: lp2475@columbia.edu).

Funding This work was supported by the Agency for Healthcare Research and Quality [grant number RO3 HSO24758].

\section{Compliance with ethical standards:}

Conflict of Interest: To the best of our knowledge, no conflict of interest, financial or other, exists for any of the authors including Dr. Lusine Poghosyan, Dr. Affan Ghaffari, Dr. Jianfang Liu, and Dr. Mark Friedberg.

\section{REFERENCES}

1. Hofer AN, Abraham J, Moscovice I. Expansion of coverage under the Patient Protection and Affordable Care Act and primary care utilization. Milbank Q. 2011;89(1):69-89. doi:https://doi.org/10.1111/j.1468-0009. 2011.00620.x

2. Schottenfeld L, Petersen D, Peikes $\mathbf{D}$, et al. Creating patient-centered team-based primary care. AHRQ Pub. No. 16-0002-EF. Rockville, MD: Agency for Healthcare Research and Quality. March 2016.

3. Mitchell P, Wynia M, Golden R, McNellis B, Okun S, Webb CE, et al Core Principles \& Values of Effective Team-Based Health Care. Washington, DC: Institute of Medicine; 2012.

4. Green LV, Savin S, Lu Y. Primary care physician shortages could be eliminated through use of teams, nonphysicians, and electronic communication. Health Aff. 2013;32(1):11-9. doi:https://doi.org/10.1377/ hlthaff.2012.1086

5. National Committee for Quality Assurance. Patient-Centered medical home Available at: http://www.ncqa.org/Programs/Recognition/Practices/ PatientCenteredMedicalHomePCMH.aspx. Accessed February 4, 2019.

6. U.S. Department of Health and Human Services Health Resources and Services Administration Bureau of Health Workforce National Center for Health Workforce Analysis. National and regional projections of supply and demand for primary care practitioners: 2013-2025. Available at: https://bhw.hrsa.gov/sites/default/files/bhw/health-workforce-analysis/research/projections/primary-care-national-projections2013-2025. pdf. Accessed February 12, 2019.

7. Barnes $\mathbf{H}$, Richards MR, McHugh MD, Martsolf G. Rural and nonrural primary care physician practices increasingly rely on nurse practitioners. Health Aff. 2018;37(6):908-14. doi:https://doi.org/10.1377/hlthaff. 2017.1158

8. Reagans R, Zuckerman EW. Networks, diversity, and productivity: the social capital of corporate R\&D teams. Organ Sci. 2001;12(4):502-17. doi:https://doi.org/10.1287/orsc. 12.4.502.10637

9. Jackson SE, Joshi A, Erhardt NL. Recent research on team and organizational diversity: SWOT analysis and implications. J Manage. 2003;29(6):801-30. doi:https://doi.org/10.1016/s0149-2063(03)00080-1

10. Jehn KA, Northcraft GB, Neale MA. Why differences make a difference: a field study of diversity, conflict and performance in workgroups. Adm Sci Q. 1999;44(4):741-63. doi:https://doi.org/10.2307/2667054

11. Mannix E, Neale MA. What differences make a difference? The promise and reality of diverse teams in organizations. Psychol Sci Public Interest. 2005;6(2):31-55. doi:https://doi.org/10.1111/j.1529-1006.2005.00022.x

12. Chatman JA. Matching people and organizations: Selection and socialization in public accounting firms. Adm Sci Q. 1991;36:459-84. doi:https://doi.org/10.2307/2393204

13. Horwitz SK, Horwitz IB. The effects of team diversity on team outcomes: a meta-analytic review of team demography. J Manage. 2007;33(6):9871015. doi:https://doi.org/10.1177/0149206307308587
14. Harrison DA, Price KH, Gavin JH, Florey AT. Time, teams, and task performance: changing effects of surface-and deep-level diversity on group functioning. Acad Manage J. 2002;45(5):1029-45. doi:https:// doi.org/10.5465/3069328

15. Milliken FJ, Martins LL. Searching for common threads: understanding the multiple effects of diversity in organizational groups. Acad Manage Rev. 1996;21(2):402-33. doi: https://doi.org/10.2307/258667

16. Brigham T, Barden C, Dopp AL, et al. Journey to construct an allencompassing conceptual model of factors affecting clinician well-being and resilience. NAM Perspectives. Discussion Paper, National Academy of Medicine, Washington, DC. 2018. https://doi.org/10.31478/201801b

17. Jackson GL, Powers BJ, Chatterjee R, et al. The patient-centered medical home: a systematic review. Ann Intern Med. 2013;158(3):169-78. doi:https://doi.org/10.2307/258667

18. DesRoches CM, Barrett KA, Harvey BE, et al. The results are only as good as the sample: assessing three national physician sampling frames. J Gen Intern Med. 2015;30(3):595-601. doi:https://doi.org/10.1007/ s11606-015-3380-9

19. Barnes H, Maier CB, Sarik DA, Germack HD, Aiken LH, McHugh MD. Effects of regulation and payment policies on nurse practitioners' clinical practices. Med Care Res Rev. 2016;74(4): 431-51. doi:https://doi.org/10. $1177 / 1077558716649109$

20. Poghosyan $\mathbf{L}, \mathbf{L i u} \mathbf{J}$. Nurse practitioner autonomy and relationships with leadership affect teamwork in primary care practices: a cross-sectional survey. J Gen Intern Med. 2016;31(7):771-7. doi:https://doi.org/10. 1007/s11606-016-3652-Z

21. Dillman DA, Smyth JD, Christian LM. Internet, Mail, and Mixed-Mode Surveys: The Tailored Design Method. 3rd ed. Hoboken, N.J: Wiley \& Sons; 2009.

22. IBM Corp. IBM SPSS Statistics for Windows, Version 24.0. Armonk: NY: IBM Corp; Released 2016.

23. Burns KJ. Classical reliability: using generalizability theory to assess dependability. Res Nurs Health. 1998;21(1):83-90. doi: https://doi.org/10. $1002 / \% 28$ SICI\%291098-240X\%28199802\%2921\%3Al<83\%3A\%3AAIDNUR9>3.0.CO\%3B2-P

24. Hosmer DW LS. Applied Logistic Regression (2nd Edition). New York, NY: John Wiley \& Sons; 2000.

25. Johnson DR, Creech JC. Ordinal measures in multiple indicator models: A simulation study of categorization error. Am Sociol Rev. 1983; 48(3):398-407. doi:https://doi.org/10.2307/2095231

26. Sullivan GM, Artino Jr AR. Analyzing and interpreting data from Likerttype scales. J Grad Med Educ. 2013;5(4):541-2. doi:https://doi.org/10. 4300/jgme-5-4-18

27. Maas CJ, Hox JJ. Sufficient sample sizes for multilevel modeling. Methodology (Gott). 2005;1(3):86-92. doi: https://doi.org/10.1027/ 1614-1881.1.3.86

28. SAS Institute Inc. Base SAS $₫ 9.4$ Procedures Guide. Cary, NC: SAS Institute Inc.; 2014.

29. Rural Health Research Center. Rural-Urban commuting area codes (RUCAs). Available at: http://depts.washington.edu/uwruca/rucacodes.php. Accessed January 20, 2019.

30. Kurtzman ET, Barnow BS. A comparison of nurse practitioners, physician assistants, and primary care physicians' patterns of practice and quality of care in health centers. Med Care. 2017;55(6):615-22. doi:https://doi.org/10.1097/mlr.0000000000000689

31. Mafi JN, Wee CC, Davis RB, Landon BE. Comparing use of low-value health care services among US advanced practice clinicians and physicians. Ann Intern Med. 2016;165(4):237-44. doi:https://doi.org/10. $7326 / \mathrm{m} 15-2152$

32. Song H, Ryan M, Tendulkar S, Fisher J, Martin J, Peters AS, et al Team dynamics, clinical work satisfaction, and patient care coordination between primary care providers: a mixed methods study. Health Care Manage Rev. 2017;42(1):28-41. doi:https://doi.org/10.1097/hmr. 0000000000000091

33. Shanafelt TD, Hasan O, Dyrbye LN, Sinsky C, Satele D, Sloan J, et al Changes in burnout and satisfaction with work-life balance in physicians and the general US working population between 2011 and 2014. Mayo Clin Proc. 2016: 90(12):1600-13. doi:https://doi.org/10.1016/j.mayocp. 2015.08.023

34. Poghosyan L, Liu J, Shang J, D'Aunno T. Practice environments and job satisfaction and turnover intentions of nurse practitioners: implications for primary care workforce capacity. Health Care Manage Rev. 2017;42(2):162-71. doi:https://doi.org/10.1097/hmr. 0000000000000094

35. Sinsky CA, Willard-Grace R, Schutzbank AM, Sinsky TA, Margolius D, Bodenheimer $\mathbf{T}$. In search of joy in practice: a report of 23 high- 
functioning primary care practices. Ann Fam Med. 2013;11(3):272-8. doi:https://doi.org/10.1370/afm.1531

36. Bodenheimer T, Sinsky C. From triple to quadruple aim: care of the patient requires care of the provider. Ann Fam Med. 2014;12(6):573-6. doi:https://doi.org/10.1370/afm.1713

37. American Association of Nurse Practitioners. NP fact sheet 2018. Available at: https://www.aanp.org/all-about-nps/np-fact-sheet. Accessed February 2, 2019.

38. Deneckere S, Euwema M, Lodewijckx C, Panella M, Mutsvari T, Sermeus W, et al. Better interprofessional teamwork, higher level of organized care, and lower risk of burnout in acute health care teams using care pathways: a cluster randomized controlled trial. Med Care. 2013;51(1):99-107. doi:https://doi.org/10.1097/mlr. Ob013e3182763312

39. American Association of Nurse Practitioners. State Practice Environment. Available at: https://www.aanp.org/advocacy/state/state-practice-environment. Accessed August 24, 2019.

Publisher's Note Springer Nature remains neutral with regard to jurisdictional claims in published maps and institutional affiliations. 